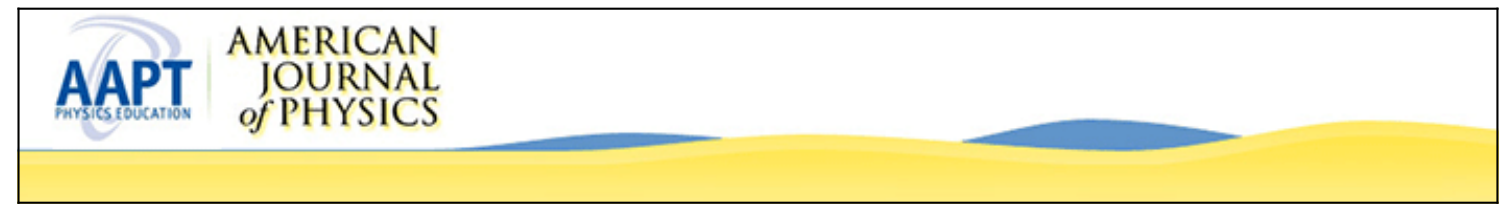

\title{
Fundamental Constants of Physics
}

E. R. Cohen, K. M. Crowe, J. W. M. DuMond, and Richard A. Beth

Citation: American Journal of Physics 27, 63 (1959); doi: 10.1119/1.1934755

View online: http://dx.doi.org/10.1119/1.1934755

View Table of Contents: http://scitation.aip.org/content/aapt/journal/ajp/27/1 ?ver=pdfcov

Published by the American Association of Physics Teachers

\section{Articles you may be interested in}

Resource Letter FC-1: The physics of fundamental constants

Am. J. Phys. 78, 338 (2010); 10.1119/1.3279700

The fundamental physical constants

Phys. Today 60, 52 (2007); 10.1063/1.2761803

Some Implications of the Cosmological Constant to Fundamental Physics

AIP Conf. Proc. 910, 381 (2007); 10.1063/1.2752487

The 1986 CODATA Recommended Values of the Fundamental Physical Constants

J. Phys. Chem. Ref. Data 17, 1795 (1988); 10.1063/1.555817

Fundamental Physical Constants

Phys. Today ; 10.1063/PT.4.0095

\section{WebAssign.}

\section{Free Physics Videos}

Add these videos and many more resources - free with WebAssign.

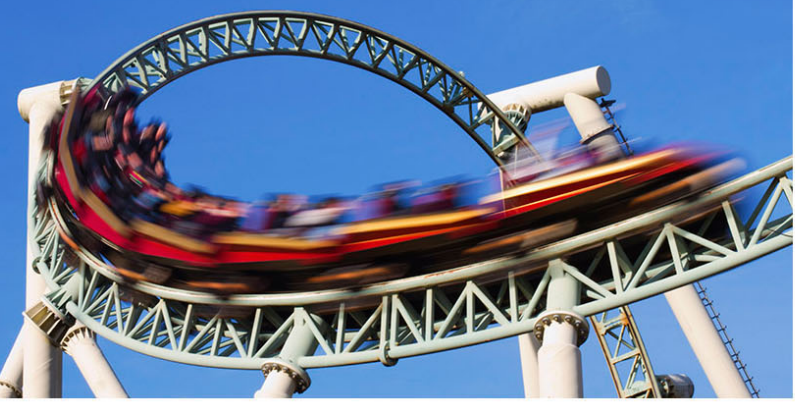


According to Rule 1 (a) the region of uncertainty of $C$ (say $c$ ) will be $(b+a)$ and calculation shows that this is indeed true:

$$
C=C_{0} \pm c=\left(B_{0} \pm b\right)-\left(A_{0} \pm a\right)=\left(B_{0}-A_{0}\right) \pm(b+a) .
$$

However, the percent uncertainty does not follow Rule 1 (b), for if we factor we have

$$
C=\left(B_{0}-A_{0}\right)\left[1 \pm \frac{b+a}{B_{0}-A_{0}}\right]
$$

in which the term $\left[(b+a) /\left(B_{0}-A_{0}\right)\right] \times 100$ is the percent uncertainty in the clearance distance. This value may be very much larger than either the percentage uncertainties $100 b / B_{0}$ or $100 a / A_{0}$. For example, let the bolt have length
$10.00 \pm 0.01 \mathrm{~cm}$ and let the depth of the hole be $10.10 \pm 0.01$ $\mathrm{cm}$. Each of these measurements has an uncertainty of $0.1 \%$. But the percent uncertainty in the clearance distance is $[(0.01+0.01) /(10.10-10.00)] \times 100=20 \%$ !

It is evident that the percent uncertainty of the result obtained by subtracting two numbers is not "of the order of magnitude of the largest percentage uncertainty present." Indeed it can be exceedingly large, approaching infinity as the difference between the two numbers approaches zero.

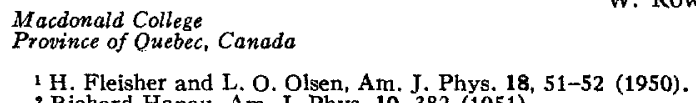

\section{ANNOUNCEMENTS AND NEWS}

\section{Book Review}

Fundamental Constants of Physics. E. R. Cohen, K. M. Crowe, and J. W. M. DuMond. Pp. 287+ix. Interscience Monographs in Physics and Astronomy, Volume 1. Interscience Publishers, Inc., New York, 1957. Price $\$ 7.50$.

Raymond T. Birge, to whom this volume is dedicated, was the author of the first paper in Volume 1 of the Reviews of Modern Physics. The paper provided a list of "Probable values of the general physical constants" as its title promised. More importantly, Birge had the courage to point out specific areas where, in all conscience, the results of different experimental approaches to the same quantity, such as $e, e / m$, or $h / e$, did not agree as well as the care and precision of the individual experiments implied they should. By this critical attitude, a dead review of things past became a live inspiration for future work.

Birge's paper set the tone for a series of later papers by himself and others, the latest of which is the book under review. The preface remarks: "A history of progress on the constants during the first half of the twentieth century is not very different from a history of physics itself during that period."

After a summary of the arbitrarily defined units and standards of physics, the text discusses classical measured constants including the gravitation constant, the normal mole volume of an ideal gas, the gas constant, the joule equivalent, and electrochemical determinations of the Faraday. There follows a chapter on the masses of atoms and mesons covering 64 pages and 206 pages - a gold mine of information for physicists in other fields.

The chapter on history of the atomic constants gives a current review of the main items discussed in Birge's original paper. It is followed by a chapter on postwar, highprecision measurements which delineates the vast improve- ments in precision that microwave methods, atomic beam techniques, and other advances have produced.

The final two chapters deal with least squares and its use for adjusting the over-determined mass of measurements to obtain the current set of recommended "best values" of the atomic constants.

The book is to be recommended for graduate students and for working physicists as a text on the methods available for measuring important physical quantities, the current best values, the history of the measurements, and the large number of original references. Two of the present authors, DuMond and Cohen, have written summary articles on the fundamental constants in Volume 35 of the Handbuch der Physik, and in the new Condon-Odishaw Handbook of Physics.

Many random general reflections will occur to the reader of a summary of such a wide range of modern physics.

For example, why does the universal constant of gravitation $G$ still stand in majestic isolation compared to atomic constants like $e, m$, and $h$ which are so strongly interrelated in many precision measurements?

The masses of atoms and mesons must now be included among the fundamental constants; will the precision of their measurement be increased as markedly in the future by the advent of new ideas and techniques as has, for example, been attained since the war with the atomic constants by exploiting the precision with which microwave frequencies can be measured?

Some very good physicists still privately object to the use of least squares for adjusting the over-determined set of atomic constant measurements, although they would never quarrel with the use of least squares in geodesy or positional astronomy. Are the relations of theoretical physics to be thought of as less real than those of geometry? Is it more comfortable not to find suggestions of discrepancies in the structure of theory and measurement? Or is 
the fear that someone will practice numerology with the results so great that we should forego the constructive value of the sharpest intercomparison of physical measurements?

RICHARD A. BETH

Brookhaven National Laboratory

\section{New Members of the Association}

The following persons have been made members or junior members of the American Association of Physics Teachers since the publication of the preceding list [Am. J. Phys. 26, 600 (1958)].

\section{Active Members}

Barton, Norman, Physics Department, University of British Columbia, Vancouver 8, British Columbia, Canada.

Brown, John S., 11 Briggsville, North Adams, Mass.

Carney, Brother J. George, St. Mary's College Library, Winona, Minn.

De Graaf, Donald E., 1909 Proctor Avenue, Flint, Mich. Denniston, Orval R., Route \#1, Box 200, Bandon, Oreg. Domb, Cyril, 37 Green Lane, London N. W. 4, England. Eckert, Thomas J., 1004 Ashland, Wilmette, Ill.

Frye, Laurel B., 420 N. Madison, Siloam Springs, Ark.

Gabel, Joseph W., Route \# 1, Box 91-A, Sugar Grove, Ohio. Kirk, Joseph P., Apt. \# 1, Allan Village, Endicott, N. Y.

Prince, Clarence E., Jr., \# 133 Ojung-ni, Taejon College, Taejon, Korea.

Rice, Michael, Physics Department, Boston University, 725 Commonwealth Avenue, Boston 15, Mass.
Romain, Jacques E., B. P. 1528, Elisabethville, Belgian Congo.

Simmons, Cary A., 3304 Clifton Avenue, Nashville 9, Tenn.

Smith, James P., Apartment 104, Hinds Junior College, Raymond, Miss.

Teller, J. Ronald, 1120 South Newton, Sioux City, Iowa.

Van Etten, Leigh C., Wayland Academy, Beaver Dam, Wis.

\section{Junior Members}

Carlson, Charles M., 1298 East Claybourne Avenue, Salt Lake City, Utah.

Coles, Marlow J., 1700 East 3350 South, Salt Lake City, Utah.

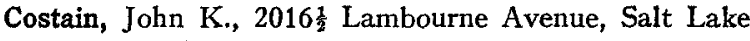
City 9, Utah.

Dallin, Dean E., 529 S. W. Temple, Salt Lake City, Utah.

Farb, Norman E., 1519 Kappa \# 1, Salt Lake City, Utah.

Geldart, James W., Wolfville, N. S., Canada.

Howard, Blaine N., 79 "S" Street, Salt Lake City, Utah.

Joenk, Rudolph J., Jr., 5117 Caste Drive, Pittsburgh 36, $\mathrm{Pa}$.

Linford, Robert G., 225 South 12th East \# 3, Salt Lake City 2, Utah.

Mackenzie, James M., 10914-82 Avenue, Edmonton, Alberta, Canada.

Petsch, Otto, 2362 Euclid Heights Boulevard, Cleveland Heights, Ohio.

Po Saw, Thein Oo, 822 12th, Golden, Colo.

Power, Dean V., 1544 Kappa \# 7, Salt Lake City, Utah.

\section{Proceedings of the American Association of Physics Teachers}

\section{Summer Meeting at the University of Colorado and National Bureau of Standards \\ Boulder, Colorado, June 25-27, 1958}

$\mathrm{T}$ HE American Association of Physics Teachers held its summer meeting at Boulder, Colorado. The University of Colorado and the National Bureau of Standards were our joint hosts. One afternoon was devoted to a joint session with the University of Colorado-College Entrance Examination Board's Conference for School and College Teachers of Physics. Members were housed in one of the University's new and attractive dormitories and dining facilities were provided in the Memorial Building of the University. One hundred and thirty-three members of the Association were registered.
The meeting opened on Wednesday morning in the auditorium of the National Bureau of Standards with a session of seven contributed papers. This was followed by a luncheon for members and guests in the Persian Room of the Memorial Building.

At the afternoon meeting, in the lecture hall of the Physics Building, greetings from University President Quigg Newton were read to the members of the Association by William B. Pietenpol, Emeritus Professor of Physics. President Newton expressed his sincere regret at being unable to welcome the group himself. Three invited papers 